\title{
Sexual Coercion and Associated Factors among Female Students of Madawalabu University, Southeast Ethiopia
}

\author{
Abulie Takele ${ }^{1}$ and Tesfaye Setegn ${ }^{2}$ \\ ${ }^{1}$ Department of Nursing, College of Medicine \& Health Sciences, Madawalabu University, 302 Bale Goba, Ethiopia \\ ${ }^{2}$ Department of Reproductive Health, College of Medicine and Health Sciences, School of Public Health, \\ Bahir Dar University, 3008 Bahir Dar, Ethiopia \\ Correspondence should be addressed to Abulie Takele; abuletakele@yahoo.com
}

Received 1 September 2014; Accepted 21 November 2014; Published 16 December 2014

Academic Editor: Ronald J. Prineas

\begin{abstract}
Copyright ( $(2014$ A. Takele and T. Setegn. This is an open access article distributed under the Creative Commons Attribution License, which permits unrestricted use, distribution, and reproduction in any medium, provided the original work is properly cited.
\end{abstract}

\begin{abstract}
Introduction. Violence against women, in its various forms, is an important social and public health problem in different communities around the world. Although violence against women is against the inalienable human right and resulted in physical, sexual, and psychological harm or suffering to women, little has been documented regarding its factors and distribution among youth population such as university students. Therefore, the objective of this study was to assess factors associated with sexual coercion among female students at Madawalabu University. Methods. This was a cross-sectional institution based study conducted on 411 female students which were selected by systematic random sampling from the list of female students. Data were collected in April 2012 using structured-interview administered questionnaire. Descriptive, binary, and multivariable logistic regression analysis were carried out using SPSS version 16. Result. In this study, the mean $( \pm S D)$ age at first sex was $18.19(+1.83)$ years. Lifetime and coercion in last twelve months were $163(41.1 \%)$ and $101(25.4 \%)$, respectively. Twenty-one $(5.9 \%)$ of the respondents were raped. Being influenced/forced into unwanted sexual act 74 (18.6\%) and having their genitalia/breast unwillingly touched 44 (11.1\%) were reported as the commonest mechanisms of coercion. Age at first sex (17-19 years) (AOR $=0.241,95 \%$ CI: 0.074, 0.765) and occasional alcohol use $(\mathrm{AOR}=4.161,95 \% \mathrm{CI}: 1.386,12.658)$ were significantly associated with coercion in the last twelve months. Conclusion. The overall lifetime sexual coercion was found to be $41.1 \%$. In this study $6.8 \%$ of female students were raped and majority have had trial of rape. But $93.75 \%$ did not report to any legal body. With the existing prevalence and identified factors, the university should work towards minimizing the risk of sexual coercion through intensifying life skill peer education and assertiveness trainings.
\end{abstract}

\section{Introduction}

Gender based violence (GBV) is a pervasive problem for most women all over the world [1-3]. Violence against women, in its various forms, is endemic in all communities and countries around the world. It affects all race, age, religious, and national boundaries [1]. According to the United Nations Declaration, violence against women includes any act of gender based violence that results in physical, sexual, and psychological harm or suffering to women, including threats or such acts as coercion or durable deprivation of liberty, whether occurring in public or private life [4].

Over the past 25 years, there is recognition of gender based violence under reporting. In addition, there are high prevalence and increased acknowledgment that it can affect women at any stage of their lives and can occur in various forms that may involve physical, psychological sexual, and/or economic abuse. Violence against women is a crucial violation of human right to liberty and freedom from fear, and now it is recognized as a priority public health and human rights issue [5]. Abuse by intimate male partners and coerced sex were the most common forms of violence against women, whether it takes place in childhood, adolescence, or adulthood [6]. This problem is more severe among young adolescents and could affect their health in different aspects including physical, mental, and social wellbeing of the victim.

Intimate partner violence and sexual violence are serious and widespread problems worldwide. In addition to 
violations of human rights, violence profoundly damages the physical, sexual, reproductive, emotional, mental, and social wellbeing of individuals and families [7]. Sexual violence thus appears to be a major challenge of school life for many adolescent females in Ethiopia and elsewhere [8].

Sexual violence is the act of forcing (or attempting to force) a female through physical body harm or any means to engage in a sexual behavior against her will. Sexual coercion exists along a continuum, from forcible rape to nonphysical forms of pressure that compels girls and women to engage in sex against their will. In some forms of coercion a woman lacks choice and faces several physical or social consequences if she resists sexual advances. Around the world, at least one woman in every three has been beaten, coerced into sex, or otherwise abused in her lifetime [6]. Much sexual coercion takes place against children or adolescents in both industrial and developing countries whereby between onethird and two-thirds of women that are sexual assault victims are young [9]. The experience of sexual coercion leads to a greater likelihood of risky sexual behavior such as early sexual debut, many sexual partners, and inconsistent condom use. Alcohol increases the likelihood of sexual assault occurring among acquaintances during social interactions. These pathways include beliefs about alcohol, deficits in higher order cognitive processing, and motor impairment induced by alcohol and peer group norms that encourage heavy drinking leading to forced sex. Studies on sexual coercion in higher learning institutions/universities in Ethiopia are limited and the problem was not well studied.

The level of sexual coercion and its factors among female students were not studied in Madawalabu University. Therefore, this study tried to assess sexual coercion among female students and associated factors as a crucial step to improve sexual health of female students in Madawalabu University. The finding from this study can be used as a baseline for further studies and as an input for policy makers and program designers. Thus the general objective of this study was to determine the prevalence and consequences and assess factors associated with it among female Madawalabu University students in southeast Ethiopia.

\section{Materials and Methods}

2.1. Study Setting and Sample. Institution based cross-sectional quantitative study was conducted in April 2012 in order to assess sexual coercion and its associated factors. The study was conducted in Madawalabu University that is located in Bale Zone, Oromia National Regional State, $430 \mathrm{~km}$ from the capital of the country, Addis Ababa, in the southeast direction. Madawalabu University is one of the public higher learning institutions established in Ethiopia in 2007. The university currently has two campuses (Goba and Robe). In the two campuses there were 3,211 regular students of which 2,484 males and 727 females were in the second year and above. The source population for the study was all female students registered in the 2nd year and above in the academic year of 2011/12. The study excluded all newly registered students that came from preparatory programs.
The study used a single population proportion to determine the sample size. The study considered a $41.8 \%$ proportion of sexual coercion that was used from a study conducted in Addis Ababa University female students [10] at $95 \%$ certainty and margin of error 0.05 . Contingency of $10 \%$ was added to increase power and compensate for possible nonresponse. And the final sample size is 411 female students. The study follows the university's nine schools, one institute, and one college. Sample size for each school was distributed according to proportion of population female students. Sampling frame was prepared by taking a list of all second year and above students from the university registrar and alumni directorate office, and systematic random sampling was employed in each school to obtain a proportionally allocated number of participants from each school/college.

2.2. Measurement. For meeting the objectives of the study the following variables were included. Dependent variable is sexual coercion including rape, assault, and harassment. The independent variables for the study wereage, previous residence, religion, ethnicity, year of study, parent marital status, student's marital status, family background including family income and money sent (provided by family member), previous sexual activity, history of coercion, and student habits (khat chewing, alcohol use, and/or smoking).

A structured questionnaire was prepared first in English and translated to Amharic and finally back-translated to English in order to ensure its consistency for selfadministration. The questionnaire was pretested in one of the departments of the university, which was not included in the study. Appropriate modification was made based on the findings of the pretest.

Data was collected by five diploma holder nurses who were trained for one day on the data collection process and the instrument for data collection. The principal investigators and two supervisors were assigned to lead the data collection, to check for completeness and consistency of a questionnaire, and to assist data collectors. Before data collection started, directors and student deans of the respective campuses and schools were approached using a letter written by the academic vice president. List of female students and selection of eligible students and questionnaire administration halls/rooms were arranged and prepared in these schools and colleges. The selected students were made to seat separately and the purpose of the study was well explained. Following a self-administered response to the questions, completed questionnaire was collected in a collection box.

2.3. Data Analysis. Data were checked for completeness, sorted, entered, cleaned, and processed by Statistical Packages for Social Science (SPSS) version 16. Analysis of association for selected exposure variables was done with the outcome variables. Logistic regression was performed using SPSS version 16 . The results were presented using figures, frequencies, proportions, odds ratio, and confidence interval.

In order to see the association between lifetime sexual coercion and explanatory variable, binary logistic regression was carried out. Those variables found to be statistically 
significant within the binary logistic regression model based on the COR and their $P$ value $(P<0.05)$ were entered into the multivariable logistic regression model to come up with final predictors of lifetime sexual coercion with their respective adjusted odds ratios.

In the interest of common understanding the operational definitions of the following words and phrases are given.

Attempted rape: it is defined as a trial to have sexual intercourse without consent of the girl but without penetration of the vagina or anus or mouth.

Consequences of sexual coercion: they include social, physical, economical, educational, and psychological status of the victim women or girl after coercion.

Economic implication: sometimes parents are forced to take their daughter out of school because they are afraid of rape or girls drop out of school after being raped or abducted which results in improper education and unemployment or poverty.

Performed rape: it is defined as any nonconsensual penetration of the vagina or anus or mouth. It is done physically or by threatening of body harm, or when the victim is incapable of giving consent.

Physical consequences: raped victims reported problems of lacerations, pregnancy/abortion, and sexually transmitted diseases (STDs) and other injuries.

Rape: it is the act of forcing a female student through violent threats and deception to engage in sexual behaviors with penetration of the vagina.

Sexual coercion: it is the act of forcing (or attempting to force) a female student through physical body harm or any means to engage in a sexual behavior against her will.

Sexual harassment: it is unwanted sexual behavior such as physical contact or verbal comments, jokes, questions, and suggestions.

\section{Results}

Three hundred ninety-seven (96.6\%) respondents completed the questionnaire administered. About two-thirds of the respondents, $242(61 \%)$, were in the age group of $20-24$ years and the mean age of the study subjects was $21.08 \pm$ $1.40 \mathrm{SD}$; the majority, 358 (90.2\%), of the respondents were not married. Two hundred twenty-four (56.4\%) were Oromo ethnic group. More than half of the respondents, 255 (64.2\%), were Orthodox; two hundred ninety-six (74.6\%) were from urban areas and the majority of the respondents, $383(96.5 \%)$, lived in the campus (Table 1).

The mean of the last semester cumulative GPA of the respondents was $2.78 \pm 0.50 \mathrm{SD}$. One hundred thirteen (28.5\%) of respondents' fathers' education levels were college/university. And eighty-two (20.7\%) of mothers of study subjects were able to read and write. Two hundred sixty $(65.8 \%)$ of respondents' mothers and fathers lived together
TABLE 1: Sociodemographic characteristics of the respondents in Madawalabu University, southeast Ethiopia, April 2012.

\begin{tabular}{|c|c|c|}
\hline Variable & Number & Percent \\
\hline \multicolumn{3}{|c|}{ Age of the respondent } \\
\hline$<20$ & 146 & 36.8 \\
\hline $20-24$ & 242 & 61.8 \\
\hline$>24$ & 9 & 2.3 \\
\hline \multicolumn{3}{|l|}{ Currently married } \\
\hline Yes & 39 & 9.8 \\
\hline No & 358 & 90.2 \\
\hline \multicolumn{3}{|l|}{ Ethnicity } \\
\hline Oromo & 224 & 56.4 \\
\hline Amhara & 105 & 26.4 \\
\hline Gurage & 28 & 7.1 \\
\hline Tigre & 20 & 5.0 \\
\hline Sidamo & 16 & 4.0 \\
\hline Others* & 4 & 1.0 \\
\hline \multicolumn{3}{|l|}{ Religion } \\
\hline Orthodox & 255 & 64.2 \\
\hline Protestant & 86 & 21.7 \\
\hline Muslim & 44 & 11.1 \\
\hline Catholic & 9 & 2.3 \\
\hline Others ${ }^{* *}$ & 3 & 0.8 \\
\hline \multicolumn{3}{|c|}{ Residence before joining university } \\
\hline Urban & 296 & 74.6 \\
\hline Rural & 101 & 25.4 \\
\hline \multicolumn{3}{|l|}{ Residence } \\
\hline In the campus & 383 & 96.5 \\
\hline Out of campus & 14 & 3.5 \\
\hline \multicolumn{3}{|l|}{ Year of study } \\
\hline Second & 229 & 57.7 \\
\hline Third & 162 & 40.8 \\
\hline Fourth & 6 & 1.5 \\
\hline
\end{tabular}

${ }^{*}$ Kembata and Somali; ${ }^{* *}$ Kale Hiwot and Missionary.

and $12(3.0 \%)$ did not have both mother and father. Threefourths, 297 (75.2\%), of the respondents were living with their family (mother and father) before joining university (Table 2).

The mean age at first sex was 18.19 years \pm 1.83 SD. One hundred ninety (47.9\%) of the respondents had constant sexual partner. And 96 (24.2\%) responded that they had had sex. Sixty-one $(64.9 \%)$ of those sexually active had started sex in their late adolescent (17-19 years). About two-thirds, $62(64.6 \%)$, of the respondents who were sexually active had started sex before joining university. Seventeen (50\%) of the respondents who started sex after joining university started sex in the second year of their study. About one-third (36.8\%) of the sexually active respondents started sex within marriage and $27(28.4 \%)$ started sex by their interest (Table 3$)$.

Thirty-six (9.1\%) of the respondents were using any of the substances always. Among the substances used were alcohol $23(5.8 \%)$, khat $11(2.8 \%)$, hashish $6(1.5 \%)$, cigarettes $(2.3 \%)$, and others $13(3.3 \%)$. Eighty-eight $(22.2 \%)$ of the respondents were using different substances sometimes. The substances 
TABLE 2: Family educational status, mother and father living situation, and students' living arrangement before joining university in Madawalabu University, southeast Ethiopia, April 2012.

\begin{tabular}{|c|c|c|}
\hline Variable & Frequency & Percentage \\
\hline \multicolumn{3}{|c|}{ Fathers' educational status } \\
\hline Illiterate & 38 & 9.6 \\
\hline Read and write & 79 & 19.9 \\
\hline $1-6$ & 60 & 15.1 \\
\hline $7-8$ & 52 & 13.1 \\
\hline $9-12$ & 55 & 13.9 \\
\hline College/university & 113 & 28.5 \\
\hline \multicolumn{3}{|c|}{ Mothers' educational status } \\
\hline Illiterate & 75 & 18.9 \\
\hline Read and write & 82 & 20.7 \\
\hline $1-6$ grades & 68 & 17.1 \\
\hline $7-8$ grades & 36 & 9.1 \\
\hline $9-12$ grades & 78 & 19.6 \\
\hline College/university & 58 & 14.6 \\
\hline \multicolumn{3}{|l|}{ Family living situation } \\
\hline Live together & 260 & 65.8 \\
\hline Divorced & 46 & 11.6 \\
\hline Father alive & 21 & 5.3 \\
\hline Mother alive & 56 & 14.2 \\
\hline Both died & 12 & 3.0 \\
\hline \multicolumn{3}{|c|}{ Living with whom before university } \\
\hline Family & 297 & 75.2 \\
\hline Mother only & 33 & 8.4 \\
\hline Father only & 9 & 2.3 \\
\hline Relatives & 24 & 6.1 \\
\hline Husband & 17 & 4.3 \\
\hline Others ${ }^{*}$ & 15 & 3.8 \\
\hline \multicolumn{3}{|l|}{ Last semester grade } \\
\hline$<2.00$ & 20 & 6.1 \\
\hline $2.01-2.50$ & 95 & 29.1 \\
\hline $2.51-3.00$ & 121 & 37.1 \\
\hline $3.01-3.50$ & 59 & 18.1 \\
\hline $3.51-4.00$ & 31 & 9.5 \\
\hline
\end{tabular}

${ }^{*}$ Nonrelatives and alone.

used were alcohol 73 (18.4\%), khat $23(5.8 \%)$, hashish 7 (1.8\%), cigarettes $11(2.8 \%)$, and others $10(2.8 \%)$.

Lifetime coercion for the study subjects was 163 (41.1\%). The mechanisms of forcing were by influencing them in unwanted sexual acts 121 (30.5\%), having their genitalia/breast unwillingly touched $86(21.7 \%)$, having faced trial of rape 20 (5.0\%), being forced into sex 13 (3.3\%), and using force for sex by frightening $8(2.6 \%)$. In the past twelve months $101(25.4 \%)$ of the respondents were coerced. The mechanisms of coercion were being influenced to unwanted sexual act $74(18.6 \%)$, having their genitalia/breast unwillingly touched $44(11.1 \%)$, having faced trial of rape $10(2.5 \%)$, and being forced into sexual act $8(2.0 \%)$.
TABLE 3: Sexual history and characterises of sexual initiation respondents in Madawalabu University, southeast Ethiopia, April 2012.

\begin{tabular}{|c|c|c|}
\hline Variable & Frequency & Percent \\
\hline \multicolumn{3}{|l|}{ Have constant sexual partner } \\
\hline Yes & 190 & 47.9 \\
\hline No & 207 & 52.1 \\
\hline \multicolumn{3}{|l|}{ Ever had sex } \\
\hline Yes & 96 & 24.2 \\
\hline No & 306 & 75.8 \\
\hline \multicolumn{3}{|l|}{ Age at first sex in years } \\
\hline $10-16$ & 14 & 14.9 \\
\hline $17-19$ & 61 & 64.9 \\
\hline$\geq 20$ & 19 & 20.2 \\
\hline \multicolumn{3}{|l|}{ When sex started } \\
\hline Before joining university & 62 & 64.6 \\
\hline After joining university & 34 & 35.4 \\
\hline \multicolumn{3}{|c|}{ At which year of study sex started } \\
\hline First & 16 & 47.0 \\
\hline Second & 17 & 50.0 \\
\hline Third & 1 & 3.0 \\
\hline \multicolumn{3}{|l|}{ How sex started } \\
\hline Within marriage & 35 & 36.8 \\
\hline Self-interest & 27 & 28.4 \\
\hline Peer pressure & 13 & 13.7 \\
\hline Friend promise & 23 & 24.2 \\
\hline For money & 6 & 6.3 \\
\hline To pass examinations & 8 & 8.4 \\
\hline Forced & 5 & 5.3 \\
\hline Intoxicated with alcohol & 1 & 1.1 \\
\hline
\end{tabular}

As a result of coercion the study subjects experienced frequent headache, poor appetite, sleeplessness, fear, selfblaming, blaming others, loss of self-value, the thought of coercion as end of life, the thought of death as being better than being coerced, and other consequences.

From the total study subjects $27(6.8 \%)$ had faced rape and nearly half (48.1\%) of the rape was committed in the perpetrators' home. The time of rape was in the afternoon 12 (44.4\%), evening 11 (40.7\%), and early morning 4 (14.8\%). Surprisingly, only 2 (6.25) of the victims of rape reported the event to legal bodies (Table 4). Boyfriends account for the highest percentage of perpetrators followed by brother's friend and neighbors (Figure 1). Following rape attack eight (28.6\%) became pregnant; four $(14.3 \%)$ faced abortion; six (21.4\%) faced genital trauma; six (21.4\%) experienced unusual vaginal discharge; four (14.3\%) developed genital swelling; and four $(14.3 \%)$ suffered from other problems.

For $14(51.9 \%)$ of rape victims the way of forcing was beating them (physical force). Moreover, nine (32.1\%) were raped after they were given alcohol. Fifty-six (49.1\%) of the mechanisms used to escape rape were by cheating with false promise. Seventeen $(47.2 \%)$ of the victims of rape did not report the event to anyone. Fear of families was the main 
TABLE 4: Ever raped, where rape was committed, time of rape event, number of rape events, and reporting rape to legal body, Madawalabu University, May 2012.

\begin{tabular}{lcc}
\hline Variable & Frequency & Percent \\
\hline Ever raped & 27 & \\
$\quad$ Yes & 370 & 6.8 \\
No & & 93.8 \\
Where rape was committed & 2 & \\
$\quad$ Victim's home & 13 & 4.4 \\
Perpetrators' home & 5 & 18.1 \\
Hotel & 7 & 25.9 \\
Outside of home & & \\
The time of rape & 12 & 44.4 \\
Afternoon & 11 & 40.7 \\
Evening & 4 & 14.8 \\
Early morning & & \\
Number of trial/complete rape events & 33 & 71.7 \\
Once & 7 & 15.2 \\
Twice & 5 & 10.9 \\
Three times & 1 & 2.2 \\
Four times & & \\
Rape events reported to legal body & 2 & 6.25 \\
Yes & 30 & 93.75 \\
No & &
\end{tabular}

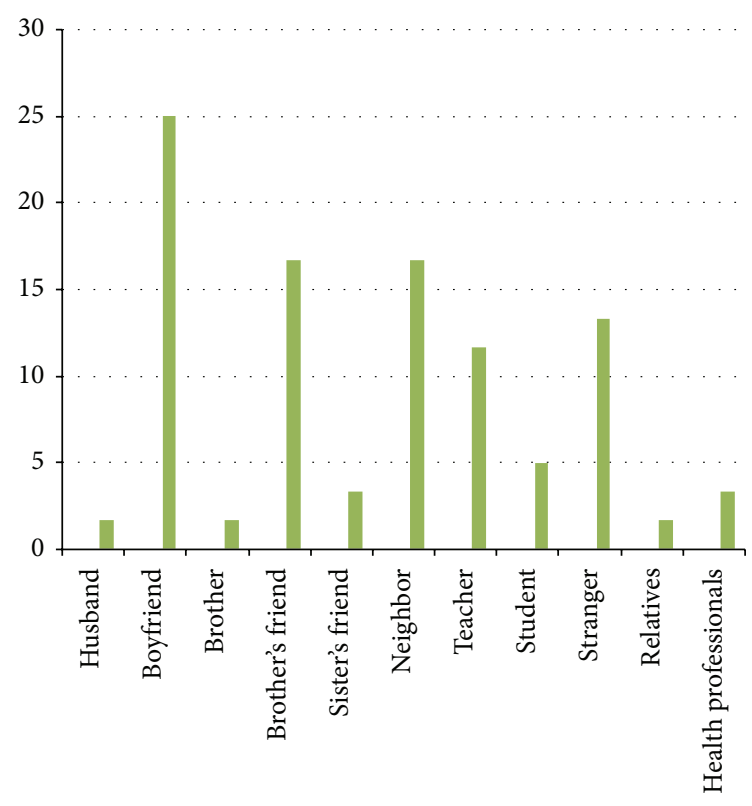

Figure 1: Percentage distribution of perpetrators of rape, Madawalabu University, May 2012.

reason for not disclosing rape $12(48.0 \%)$, followed by not knowing what to do 7 (28.0\%) (Table 5).

In order to see the association between lifetime sexual coercion and explanatory variable, binary logistic regression was carried out. Those variables found to be statistically significant within the binary logistic regression model based
TABLE 5: Ways of raping, mechanism used to escape, to whom rape was reported, and reason for not reporting rape, Madawalabu University, May 2012.

\begin{tabular}{|c|c|c|}
\hline Variable & Frequency & Percent \\
\hline \multicolumn{3}{|l|}{ Way of force used for rape } \\
\hline Biting & 14 & 51.9 \\
\hline Showing knife & 2 & 7.1 \\
\hline Giving alcohol & 9 & 32.1 \\
\hline Giving drugs with alcohol & 2 & 7.4 \\
\hline Making pass examinations & 2 & 7.4 \\
\hline Giving money & 2 & 7.4 \\
\hline \multicolumn{3}{|l|}{$\begin{array}{l}\text { Mechanisms used to escape rape by those } \\
\text { who escaped rape }\end{array}$} \\
\hline Crying to call for help & 9 & 7.9 \\
\hline Just escaped & 27 & 23.7 \\
\hline By cheating with promise & 56 & 49.1 \\
\hline Fighting & 15 & 6.1 \\
\hline Others & 7 & 13.2 \\
\hline \multicolumn{3}{|l|}{ To whom rape was reported } \\
\hline Anyone & 17 & 47.2 \\
\hline Friend & 10 & 27.8 \\
\hline Sisters & 3 & 8.3 \\
\hline Health professionals & 8 & 22.2 \\
\hline Others & 1 & 2.9 \\
\hline \multicolumn{3}{|l|}{ Reason for not disclosing rape } \\
\hline Did not know what to do & 7 & 28.0 \\
\hline Afraid of families & 12 & 48.0 \\
\hline Afraid of community & 5 & 20.0 \\
\hline Afraid of perpetrator & 6 & 24.0 \\
\hline Think legal bodies do not function & 2 & 8.0 \\
\hline Others & 1 & 4.0 \\
\hline
\end{tabular}

on the COR and their $P$ value $(P<0.05)$ were entered into the multivariable logistic regression model to come up with final predictors of lifetime sexual coercion with their respective adjusted odds ratios.

Variables which were associated with lifetime sexual coercion were having constant sexual partner $(\mathrm{COR}=0.556$, 95\% CI: $0.371,0.833)$, having had sex $(\mathrm{COR}=0.618(95 \%$ CI: $0.399,0.982)$ ), being in the age group between $17-19$ years at first sex $(\mathrm{COR}=0.249,95 \% \mathrm{CI}: 0.061,0.560)$, using substances sometimes (COR $=3.102,95 \%$ CI: 1.899, 5.068), having money sent enough $(\mathrm{COR}=1.627,95 \% \mathrm{CI}: 1.069$, $2.477)$, and using alcohol sometimes $(\mathrm{COR}=3.102,95 \% \mathrm{CI}$ : $1.899,5.068)$. Considering the AOR it was found out that only age of between 17 and 19 years at first sex $(\mathrm{AOR}=0.241$, 95\% CI: $0.074,0.765$ ) and use of alcohol sometimes (AOR $=4.161(1.386,12.658))$ were predictors of lifetime sexual coercion (Table 6). All the other variables were checked for their association and did not show statistically significant association (Table 6). 
TABLE 6: Association of lifetime coercion and behavioral characteristics of respondents in Madawalabu University, southeast Ethiopia, May 2012.

\begin{tabular}{|c|c|c|c|c|}
\hline \multirow{2}{*}{ Variable } & \multicolumn{2}{|c|}{ Lifetime coercion } & \multirow{2}{*}{ Crude OR with 95\% CI } & \multirow{2}{*}{ Adjusted OR with 95\% CI } \\
\hline & No $(\%)$ & Yes (\%) & & \\
\hline \multicolumn{5}{|c|}{ Have constant sexual partner } \\
\hline No & $98(51.6)$ & $92(48.4)$ & 1.00 & 1.00 \\
\hline Yes & $136(65.7)$ & $71(34.3)$ & $0.556(0.371,0.833)$ & $1.409(0.463,4.298)$ \\
\hline \multicolumn{5}{|c|}{ Ever had sex } \\
\hline No & $48(50.0)$ & $48(50.0)$ & 1.00 & 1.00 \\
\hline Yes & $186(61.8)$ & $115(38.2)$ & $0.618(0.399,0.982)$ & $0.534(0.289,1.102)$ \\
\hline \multicolumn{5}{|c|}{ Age at first sex } \\
\hline $10-16$ & $43(57.3)$ & $32(42.7)$ & 1.00 & 1.00 \\
\hline $17-19$ & $5(26.3)$ & $14(73.7)$ & $0.249(0.061,0.560)$ & $0.241(0.074,0.765)$ \\
\hline \multicolumn{5}{|c|}{ Using substance always } \\
\hline No & $214(59.3)$ & $147(40.7)$ & 1.00 & 1.00 \\
\hline Yes & $20(55.6)$ & $16(44.4)$ & $1.165(0.584,2.322)$ & $0.455(0.093,2.229)$ \\
\hline \multicolumn{5}{|c|}{ Using substance sometimes } \\
\hline No & $201(65.0)$ & $108(35.0)$ & 1.00 & 1.00 \\
\hline Yes & $33(37.5)$ & $55(62.5)$ & $3.102(1.899,5.068)$ & $3.230(0.277,2.229)$ \\
\hline \multicolumn{5}{|c|}{ Money sent enough } \\
\hline No & $165(63.0)$ & $97(37.0)$ & 1.00 & 1.00 \\
\hline Yes & $69(51.1)$ & $66(48.9)$ & $1.627(1.069,2.477)$ & $0.995(0.380,2.603)$ \\
\hline \multicolumn{5}{|c|}{ Using alcohol sometimes } \\
\hline No & $25(33.8)$ & $49(66.2)$ & 1.00 & 1.00 \\
\hline Yes & $209(64.7)$ & $114(35.3)$ & $3.102(1.899,5.068)$ & $4.161(1.386,12.658)$ \\
\hline
\end{tabular}

\section{Discussion}

This study identified sexual coercion and its associated factors. The lifetime prevalence of coercion in this study was found to be $41.1 \%$. This finding was less than the finding in Uganda, 31.1\% (94), but very much less than prevalence of sexual harassment in high schools of Addis Ababa [2]. This difference could be due to the difference in the setting of the study area [11].

The study tried to show the forms of coercion as physical, sexual, and psychological. As a result of coercion the study subjects experienced frequent headache, poor appetite, sleeplessness, easy fear, self-blaming, blaming others, loss of self-value, the thought of coercion as end of life, equating of coercion to death, and other consequences. These were also the consequences identified in Addis Ababa University [10]. The perpetrators of sexual coercion were relatives, husbands, teachers, strangers, boyfriends, and health professionals which is similar to the finding of Nigerian university [12]. The coercion was perpetrated by both intimate and nonintimate persons using physical force, psychological influence, and intoxication by alcohol [3].

Intimate partner violence is worldwide [7] and the consequences of sexual violence are a serious problem worldwide whether it is caused by intimate partner or stranger [13]. In this study $6.8 \%$ of the respondents reported they were raped which is higher than the finding in Nigerian university $(3.2 \%)$ [12] and lower than the finding of Addis Ababa University $(12.7 \%)$ [10]. Only $3.2 \%$ had reported the rape event to legal bodies and $28.3 \%$ of the victims were raped more than two times. The prevalence of rape among Jijiga and Addis Ababa Universities students was $15.1 \%$ and $12.7 \%$, respectively $[10,14]$. In Addis Ababa University $6.4 \%$ of the victims had reported the event to legal body. In Nigeria University only $3.2 \%$ of rape victims had reported the event to police [15]. After rape attack the victims faced unwanted pregnancy, abortion, genital trauma, unusual vaginal discharge, genital swelling, and other problems. These are also similar to the findings of other studies $[10,12,15]$.

In this study, $24.2 \%$ of the respondents were sexually active but in Addis Ababa University and Jijiga University $25.8 \%$ and 35.9 , respectively, were sexually active $[10,14]$. This may indicate that in our study area students' sexual practice was less or they may not tell that they are sexually active. In this study, the age of initiating sex (sexual debut) was 18.19 years. In a study conducted in northeast Nigeria and Cameroon the mean age at first sex was 16.1 and 15.3 years, respectively $[15,16]$, whereas in Addis Ababa and Jijiga Universities the mean age at first sex was 18.75 and 17.59 years, respectively $[10,14]$. In a study on high school students in Addis Ababa, the mean age at first sex was 18.5 years [2]. Studies conducted on sexual behavior of youth in Ethiopia revealed that the mean age at first sex in Dessie town was 17.18 years [17], in Nekemte town in western Ethiopia was 15.2 years [18], and in high schools in Harar (east Ethiopia) was 16 years [19]. These differences could be due to difference in factors for starting sex early such as perception of the respondents about early sexual practice and knowledge of the effects of early 
sexual initiation. Early initiation of sexual practice could lead to early pregnancy, thereby predisposing the girl to unwanted pregnancy, its complication such as sexually transmitted infection including HIV/AIDS, and physical injuries such as laceration of the genital tract.

In this study $64.9 \%$ of the respondents have started sex in the late adolescent $17-19$ years. More than one-third (35.4\%) of the respondents started sex after joining university which is much higher than the proportion of students who started sex after joining university in Haramaya University $(22.8 \%)$ [20]. In this study $50.0 \%$ of those who started sex after joining university started sex in the first year of study. In a study conducted in Jijiga University $92.2 \%$ of sexually active students who had sex had started sex before joining university [14]. In this study $65.2 \%$ of those sexually active had started sex willingly whereas $37.9 \%$ had started sex by the pressure from their peers and friends. This finding was inconsistent with the findings of Jijiga University [14]. This is indicative of the need for providing intensive education for students joining university by designing different approaches like life skill and peer education training [21]. And this could be due to lack of assertiveness and the fact that they are unable to negotiate safe sex and decide responsibly.

The other impressive finding of this study was $38.9 \%$ transactional sex, which is sex to any benefit from the partner at the time of initiating sex. The benefits mentioned in this study were friend promise $(24.2 \%)$, gain of money $(6.3 \%)$, and passing of examinations (8.4\%). Transactional sex was a problem as it may open the gate to risky sexual relation.

From those who were sexually active only $36.8 \%$ started sex with marriage, while for $63.2 \%$ of them sexual activity was premarital. The high prevalence of premarital sex would likely increase the risk of sexually transmitted infections including HIV/AIDS and unwanted pregnancy. In Addis Ababa University the reasons mentioned for initiating sex before marriage were self-interest, peer influence, friend promise, getting money, being forced, and others [10]. These were also the reasons mentioned for the initiation of sexual intercourse by adolescents in Nekemte town [18]. Peer influences have significant effect on early initiation of sex which is risk behavior $[6,8]$.

The study shows that $9.1 \%$ of the respondents use substance always whereas $22.2 \%$ use only sometimes. Alcohol and khat were the most widely used by the respondents. Using such substances was a risk for problems of unsafe sexual practices that predispose them to sexually transmitted infections including unwanted pregnancy, HIV/IDS, and other consequences of unsafe sex. These problems were also the problems faced by university students in China and Sweden [22, 23]. In Addis Ababa 22.0\% use alcohol and $8.0 \%$ chew khat [10]. In Jijiga University $29.5 \%$ use alcohol sometimes and $16.6 \%$ chew khat $[10,14]$. Substance use including alcohol is a risk factor for risky sexual behavior $[24,25]$. If the students and/or their partner/s were using alcohol it may result in altered behavior that leads to violence.

Following coercion the victims faced sexual and reproductive health problems such as unwanted pregnancy, abortion, genital trauma, genital swelling, and unusual vaginal discharge. This is similar to the finding of Addis Ababa and
Jijiga Universities $[10,14]$. These adolescents need help and support in order to protect them from such health risks of risky sexual relation [26]. Such violence is a violation of sexual rights of a person and a human right violation at large. These consequences have an impact on the physical, mental, and psychosocial wellbeing of the victim.

\section{Conclusion and Recommendation}

In conclusion, the study has found that coercion is prevalent in the study area and has illustrated the contribution of several factors to sexual coercion. The educational approach to life skills and peer education for students could avert the problem. Therefore the university should strengthen the sexual and reproductive health services. Using substances including alcohol needs to be avoided in order to reduce the risk of sexual coercion and mitigate its impact.

Madawalabu University is expected to work towards minimizing the risk of sexual coercion and its consequences by implanting strategies like life skill, peer education, and assertive training and strengthening youth friendly services through different outlets.

\section{Ethical Approval}

Before the actual data collection process, ethical clearance was obtained from the Ethical Review Committee of Madawalabu University. Informed consent was obtained from the study participants after brief explanation of the purpose of the study was made. Name of the respondent was excluded from the questionnaire to ensure confidentiality and anonymity of the participants' information.

\section{Conflict of Interests}

The authors declare that there is no conflict of interests regarding the publication of this paper.

\section{Authors' Contribution}

Abulie Takele and Tesfaye Setegn have taken a leading role in writing the proposal, submission, and follow-up for ethical review, data collection, data entry and analysis, and writing of the preliminary results. All authors read and approved the final paper.

\section{Acknowledgments}

The authors would like to acknowledge Madawalabu and Bahir Dar Universities and respective Medical and Health Science Colleges where they are based for their technical support. They also would like to thank Dr. Alemu Disasa for language editing and data collectors and participants.

\section{References}

[1] WHO, Putting Women First Ethical and Safety Recommendation for Research on Domestic Violence Against Women, WHO, Geneva, Switzerland, 2001. 
[2] G. Lelissa and L. Yusuf, "A cross sectional study on prevalence of gender based violence in three high schools, Addis Ababa, Ethiopia," Ethiopian Journal of Reproductive Health, vol. 2, no. 1, 2008.

[3] National of Institute Justice, The Campus Sexual Assault Study Final Report, National of Institute Justice, Washington, DC, USA, 2005-2007.

[4] United Nation General Assembly, Declaration on the Elimination of Violence Against Women, 1993.

[5] WHO, Violence Against Women: Aphordis Health Issue, WHO, Geneva, Switzerland, 1997.

[6] "Ending Violence against Women: 2003 Series," Population Reports 11, 2003.

[7] WHO, Preventing Intimate Partner and Sexual Violence Against Women. Taking Action and Generating Evidence, WHO, Geneva, Switzerland, 2010.

[8] A. Bleached, Determinants of Sexual Violence Among Ethiopian Secondary School Students, BV. Ridderkerk, Ridderkerk, The Netherlands, 2012.

[9] L. Heise, J. Pitanguy, and A. German, "Violence against women: the hidden health burden," Social Science \& Medicine, vol. 39, pp. 233-245, 1994.

[10] S. Tadesse, Assessment of sexual coercion among Addis Ababa university students [Masters thesis], Addis Ababa University, Medical Faculty Department of Public Health, Addis Ababa, Ethiopia.

[11] Chemonics International, "Women's Legal Rights Initiative: Regional Centre for Africa (RCSA) Assessment and Analysis Report August 19-September 11, 2003, Jan. 14, 2004," http://www.usaid.gov/our_work/cross-cutting_programs/wid/ pubs/wlr_rcsa.pdf.

[12] Z. Iliyasu, I. S. Abubakar, M. H. Aliyu, H. S. Galadanci, and H. M. Salihu, "Prevalence and correlates of gender-based violence among female university students in Northern Nigeria," African Journal of Reproductive Health, vol. 15, no. 3, pp. 111-119, 2011.

[13] Population Council, "Sexual and gender based violence in Africa: issues for programming 2008," http://www.popcouncil .org/.

[14] A. T. Jema, Sexual experiences and their correlate3s among Jijiga University students [M.S. thesis], Addis Ababa University, Addis Ababa, Ethiopia, 2011.

[15] A. Abby, Alcohol-Related Sexual Assault: A Common Problem among College Students, Department of Community Medicine, Wayne State University, Detroit, Mich, USA, 2002.

[16] P. Foumane, A. Chiabi, C. Kamdem, F. Monebenimp, J. S. Dohbit, and R. E. Mbu, "Sexual activity of adolescent school girls in an urban secondary school in cameroon," Journal of Reproduction and Infertility, vol. 14, no. 2, pp. 85-89, 2013.

[17] F. Mazengia and A. Worku, "Age at sexual initiation and factors associated with it among youths in North East Ethiopia," Ethiopian Journal of Health Development, vol. 23, no. 2, 2009.

[18] A. Seme and D. Wirtu, "Premarital sexual practice among school adolescents in Nekemte Town, East Wollega," Ethiopian Journal of Health Development, vol. 22, no. 2, pp. 167-173, 2008.

[19] A. J. Mason-Jones, C. Crisp, M. Momberg, J. Koech, P. de Koker, and C. Mathews, "A systematic review of the role of schoolbased healthcare in adolescent sexual, reproductive, and mental health," Systematic Reviews, vol. 1, no. 1, article 49, 2012.

[20] T. Dingeta, L. Oljira, and N. Assefa, "Patterns of sexual risk behavior among undergraduate university students in Ethiopia: a cross-sectional study," Pan Africa Medical Journal, vol. 12, article 33, 2012.
[21] R. Adhikari and J. Tamang, "Premarital sexual behavior among male college students of Kathmandu, Nepal," BMC Public Health, vol. 9, article 241, 2009.

[22] Q. Ma, M. Ono-Kihara, L. Cong et al., "Early initiation of sexual activity: a risk factor for sexually transmitted diseases, HIV infection, and unwanted pregnancy among university students in China," BMC Public Health, vol. 9, article 111, 2009.

[23] C. Gunby, A. Carline, M. A. Bellis, and C. Beynon, "Gender differences in alcohol-related non-consensual sex; cross-sectional analysis of a student population," BMC Public Health, vol. 12, article 216, 2012.

[24] A. Agardh, K. Odberg-Pettersson, and P.-O. Östergren, "Experience of sexual coercion and risky sexual behavior among Ugandan university students," BMC Public Health, vol. 11, article 527, 2011.

[25] S. E. Toscano, "A grounded theory of female adolescents' dating experiences and factors influencing safety: the dynamics of the Circle," BMC Nursing, vol. 6, article 7, 2007.

[26] H. D. Boonstra, "Young people need help in preventing pregnancy and HIV; how will the world respond?" Guttmacher Policy Review, vol. 10, no. 3, 2007. 


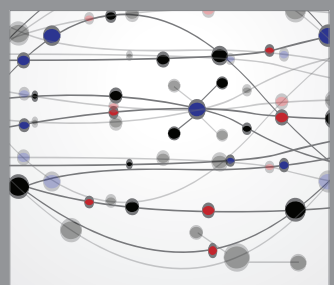

The Scientific World Journal
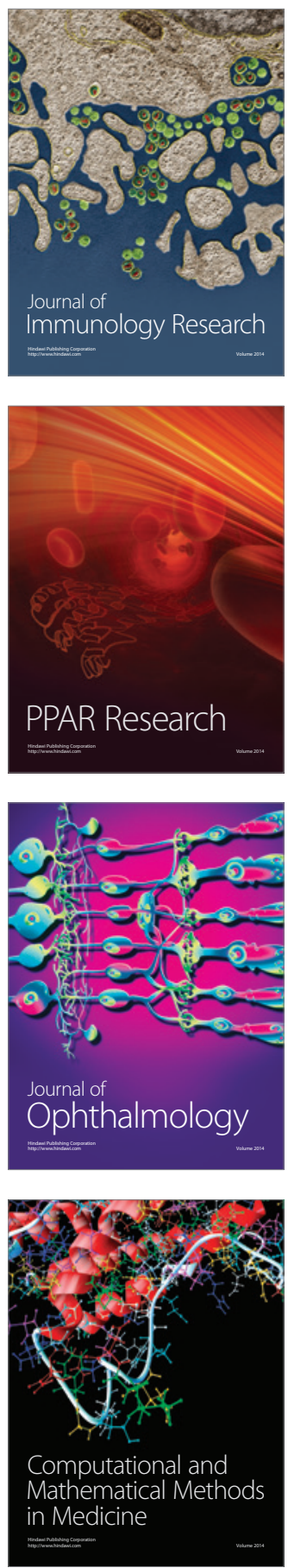

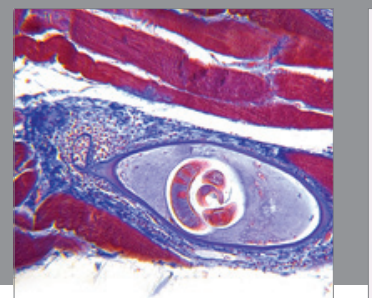

Gastroenterology

Research and Practice
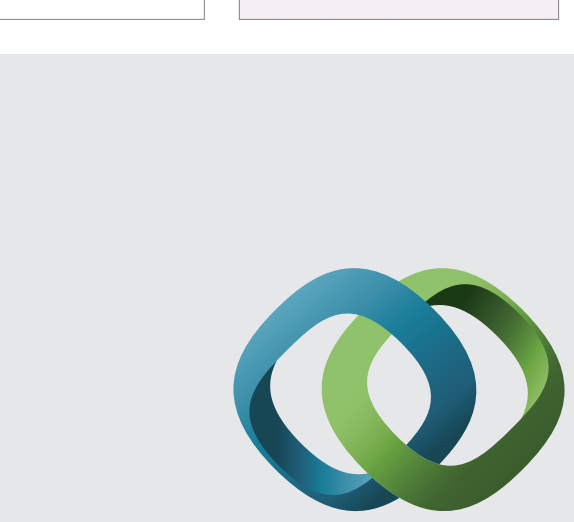

\section{Hindawi}

Submit your manuscripts at

http://www.hindawi.com
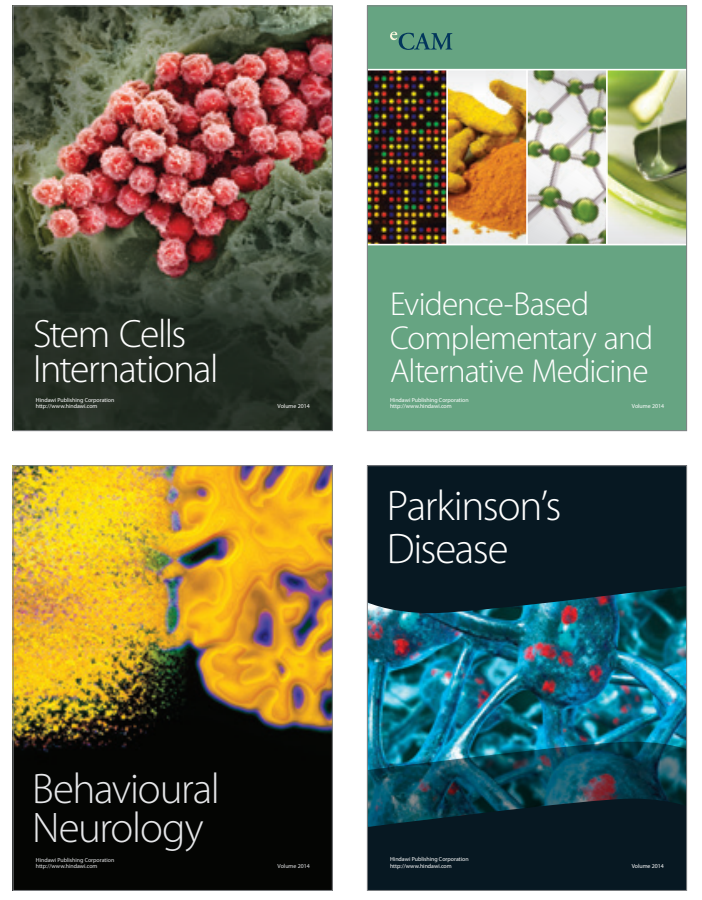
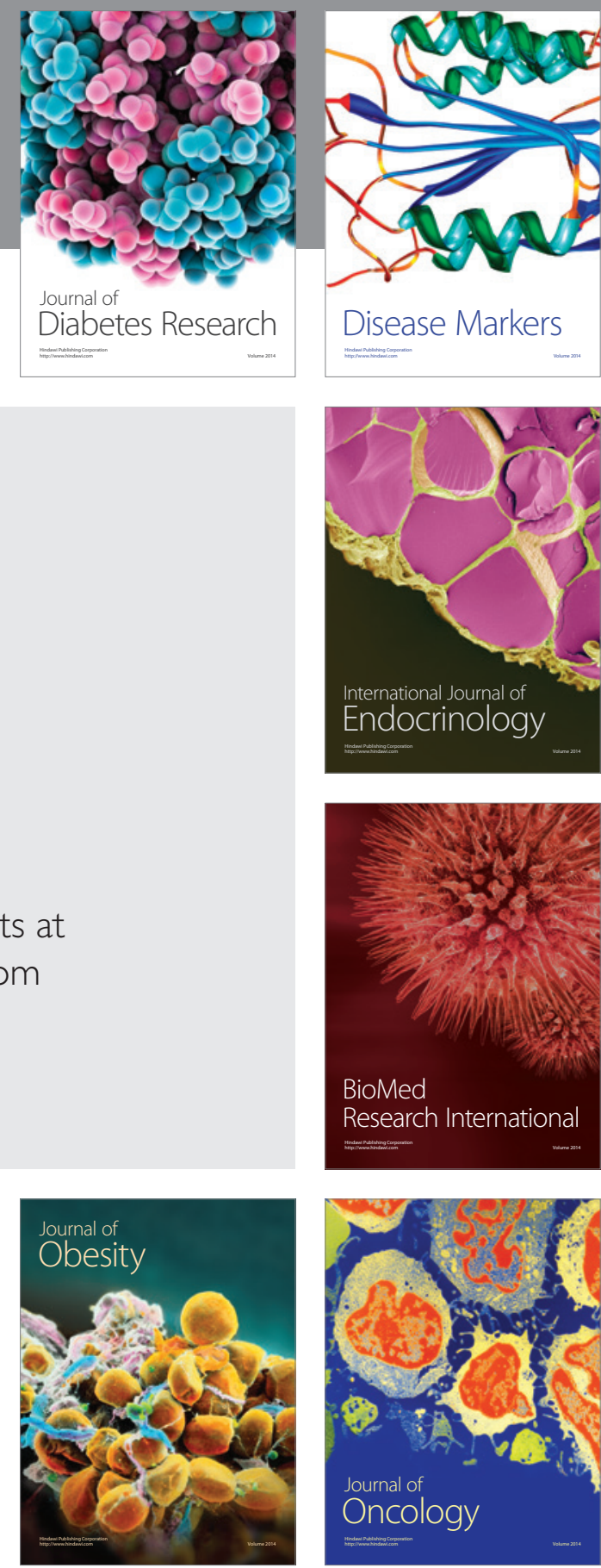

Disease Markers
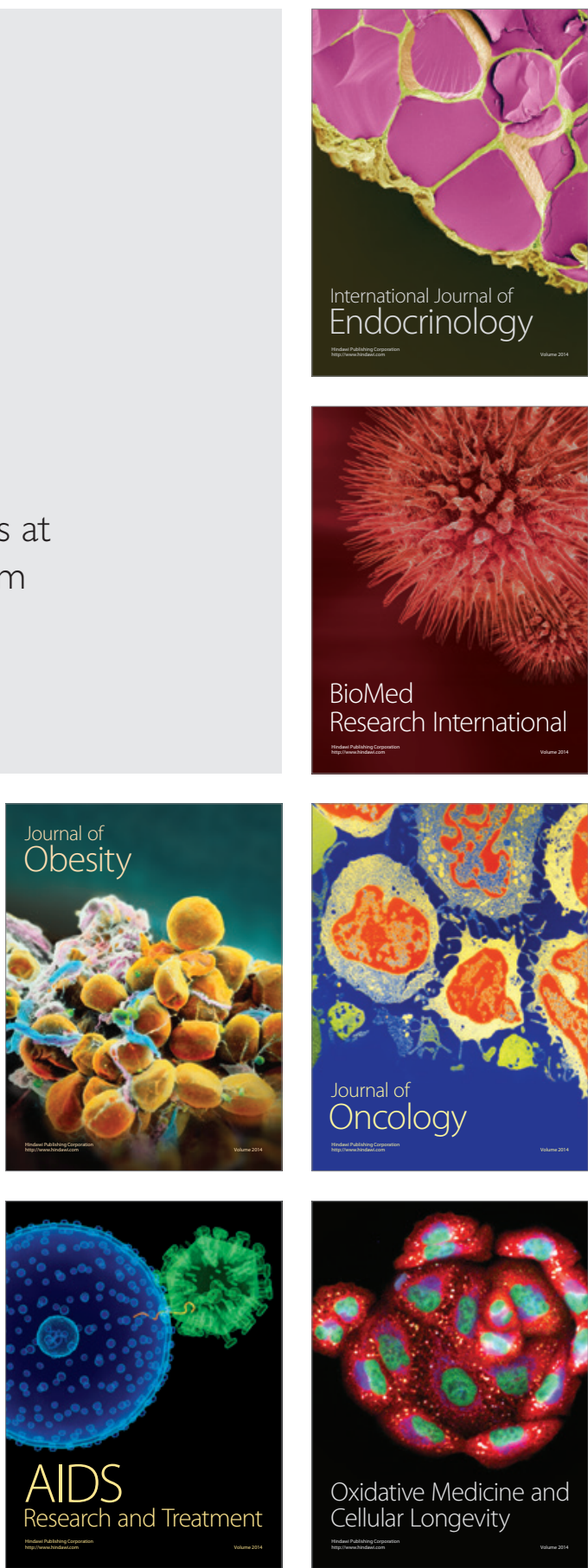